\title{
PerCursos
}

\section{A formação escolar secundária de agentes intelectuais no sul do Mato Grosso (1931-1961)}

\section{Resumo}

Este artigo tem como objetivo compreender como agentes intelectuais no sul do Mato Grosso representam em suas memórias a formação no ensino secundário no período de 1931 a 1961. Utilizaram-se como fontes de pesquisa, obras memorialísticas e relatos orais, cruzados com documentos de instituições escolares de ensino secundário da cidade de Campo Grande e Corumbá. Foram investigadas as trajetórias dos autores Abílio Leite de Barros, estudante do Colégio Santa Teresa; Pierre Adri e José Corrêa Barbosa, estudantes do Colégio Dom Bosco, por meio de suas produções memorialísticas. Tais fontes foram analisadas a partir da teoria de Pierre Bourdieu (2004, 2012), em diálogo principalmente com as noções de campo, habitus e capitais. Foram identificados no campo educacional, intensas disputas entre defensores da pedagogia tradicional e da escolanovista. $\mathrm{O}$ ensino secundário, com um currículo literário, conformava-se como reduto de formação das elites intelectuais. No sul de Mato Grosso, as instituições de ensino secundário que haviam sido recentemente instaladas ofereceram às classes economicamente favorecidas um ensino tradicional, com currículo predominantemente literário, que proporcionava acúmulo de capitais social, cultural e simbólico - que mais tarde auxiliaram a inserção dos estudantes no campo intelectual. Tal inserção foi legitimada pelas disposições incorporadas nas instituições por meio de práticas culturais, escolares, sociais e religiosas. Em que pese as fragilidades das instituições do sul de Mato Grosso nesse período de implantação e organização do ensino secundário, elas alcançaram renome e cumpriram a função de reprodução das desigualdades sociais.

Palavras-chave: Ensino secundário - História. Memória. Intelectuais. Mato Grosso.
Heloise Vargas de Andrade

Mestre em Educação pela

Universidade de Mato Grosso do

Sul-UFMS. Professora da Rede

Pública Municipal de Campo

Grande/MS.

Brasil

prof.heloisevargas@gmail.com

\section{Jacira Helena do Valle Pereira}

\section{Assis}

Doutora em Educação pela

Universidade de São Paulo - USP.

Professora da Universidade

Federal de Mato Grosso do Sul -

UFMS e do quadro permanente

do Programa de Pós-graduação em Educação/ FAED/UFMS.

Brasil

jpereira.dou@terra.com.br

\footnotetext{
Para citar este artigo:

ANDRADE, Heloise Vargas de; ASSIS, Jacira Helena do Valle Pereira A formação escolar secundária de agentes intelectuais no sul do Mato Grosso (1931-1961). Revista PerCursos, Florianópolis, v. 21, n.45, p. 232 - 255, jan./abr. 2020.
}

DOI: $10.5965 / 1984724621452020232$

http://dx.doi.org/10.5965/1984724621452020232 


\title{
The secondary school training of intellectual agents in the south of Mato Grosso (1931- 1961)
}

\begin{abstract}
This paper aims to understand how intellectual agents in Mato Grosso represent in their memories the building of secondary teaching from 1931 to 1961. It was based on researches of memorialistic work and oral reports taking into account documents of secondary teaching educational institutions from the cities of Campo Grande and Corumbá. It verified the trajectory of authors: Abílio Leite de Barros a student of Santa Teresa school; Pierre Adri and José Corrêa Barbosa students of Dom Bosco school, through their memorialistic productions. Those sources were analyzed from a Pierre Bourdieu $(2004,2012)$ theory perspective, communicating mainly with the notion of countryside, costumes, capital. It identified in the educational field intense contests between the traditional pedagogy and escolanovistas. Secondary teaching, based on a literary curriculum, was the base of intellectual elite formation. In the south of Mato Grosso secondary teaching schools which had been recently settled offered to economically favored classes a traditional teaching, being its curriculum predominantly literary which led to capital accumulation being it social, cultural and symbolic, which later on helped in the insertion of those students in the intellectual field. Such insertion was legitimatized by the disposal incorporated in the institutions through cultural, scholastic, social and religious practices. Regarding Mato Grosso do Sul institution fragilities during the time of implementation and organization of secondary teaching they achieved renown and fulfilled the reproduction of social inequalities role in society.
\end{abstract}

Keywords: Secondary teaching - History. Memory. Intellectuals. Mato Grosso. 


\section{Introdução}

O presente estudo tem como objetivo compreender como agentes intelectuais no antigo ${ }^{1}$ sul do Mato Grosso representam, em suas memórias, a formação no secundário, no período que compreende os anos de 1931 a 1961. O período selecionado para a pesquisa marca uma maior organização do campo escolar da região, e os primeiros cursos de ensino secundário passaram a funcionar de maneira mais estruturada nas cidades de Campo Grande e Corumbá.

A organização do ensino secundário também avançou na política educacional no ano de 1931 com a Reforma Francisco Campos². O ano de 1961, por sua vez, marcado pela Lei de Diretrizes e Bases 4.024/61, acabou “[...] resultando em um golpe definitivo à supremacia dos estudos clássicos na educação secundária.” (SOUZA, 2009, p. 88).

O ensino secundário propiciou uma sólida e referenciada formação humanística de agentes intelectuais, visto que esse nível de ensino instrumentalizou os jovens secundaristas a percorrerem uma trajetória principalmente na posição de docentes, jornalistas, advogados e escritores.

Parte-se da compreensão do ensino secundário como a etapa da escolarização formal que sucedia o ensino primário - equivalente ao que é hoje a segunda etapa do ensino fundamental ( $6^{\circ}$ ao $9^{\circ}$ ano) e o ensino médio. De igual forma, o ensino secundário preparava os jovens estudantes para o ingresso no ensino superior. De acordo com Souza,

Tratava-se da educação de um grupo social muito restrito, jovens herdeiros de oligarquia agrária, filhos de industriais, grandes comerciantes, profissionais liberais ou da incipiente classe média urbana, cuja formação fundamentada nos estudos desinteressados expressava a distinção cultural de uma elite, destinando-se a uma

\footnotetext{
${ }^{1}$ Em 11 de outubro de 1977, por meio da Lei Complementar n. 31, deu-se a divisão do Estado de Mato Grosso e a criação do Estado de Mato Grosso do Sul, onde estão localizadas as cidades de Campo Grande e Corumbá.

2 Em 1931, foi publicado por Francisco Campos um conjunto de leis e decretos que regulamentava os diversos níveis e modalidades de ensino, instituindo uma reforma que inovava ao dar maior organicidade ao ensino secundário, dividir o curso em dois ciclos e estabelecer uma diminuição do caráter humanista, por meio de uma "[...] distribuição mais equilibrada entres estudos literários e científicos." (SOUZA, 2008, p. 153).
} 
finalidade muito específica, isto é a preparação para os cursos superiores. (SOUZA, 2008, p. 89).

O ensino secundário foi organizado e construído como parte do processo de modernização da sociedade brasileira. O currículo majoritariamente humanístico cumpriria um papel desligado da formação profissional, visando à formação do espírito e do preparo ao trabalho intelectual, baseado na arte de bem falar e bem escrever. Esse caráter humanístico, com sua dinâmica organizacional, reafirmava o ensino secundário como uma etapa privilegiada de ensino; esteve conformado como ramo de estudos altamente elitista e seletivo, educando principalmente jovens oriundos das classes economicamente favorecidas e formando os dirigentes dos mais altos cargos da sociedade brasileira em diversos campos sociais.

Os autores - Abílio Leite de Barros, ex-aluno do Colégio Santa Teresa em Corumbá, e Pierre Adri e José Corrêa Barbosa ex-alunos do Colégio Dom Bosco em Campo Grande -, compuseram o corpus de estudantes do prestigioso ensino secundário, na porção sul do estado de Mato Grosso e trilharam uma trajetória de êxito.

As produções memorialísticas e relatos orais, por meio de entrevistas semiestruturadas 3 dos referidos estudantes secundaristas, foram utilizadas como fontes de pesquisa e cruzadas com documentos de instituições escolares em que estudaram. Tais fontes foram analisadas a partir do referencial teórico de Pierre Bourdieu, tendo em vista as noções de campos, habitus e capitais.

No período selecionado para a pesquisa foram identificadas, no campo educacional, intensas disputas entre defensores da pedagogia tradicional e da escolanovista. Isso porque o ensino secundário, com um currículo literário, sofria recorrentes denúncias em relação à ineficiência do ensino, que desencadearam sucessivas reformas a fim de democratizar o acesso à instrução secundária, com discussões e propostas relacionadas ao movimento escolanovista.

\footnotetext{
3 As entrevistas semiestruturadas foram devidamente aprovadas e protocoladas pelo Comitê de Ética, pelo Parecer 1.514.622. Os participantes foram contatos via telefone e realizadas em suas residências no ano de 2016 - falta algum conectivo na frase. Está sem coesão. Na época, Abílio Leite de Barros, 87 anos, Pierre Adri com 67 anos e, José Correia Barbosa, com 79 anos de idade.
} 
O presente artigo está organizado em dois tópicos, a saber: A escola secundária e os aspectos sociais da formação das "elites" intelectuais, que se propõe a apresentar a formação intelectual prevista na legislação do ensino secundário; e "A formação escolar de agentes intelectuais no sul de Mato Grosso: leituras em fontes de memória”, que trabalha com as questões evidenciadas por essas fontes.

\section{A escola secundária e os aspectos sociais da formação das "elites" intelectuais}

Durante a primeira metade do século XX, o ensino secundário constituiu-se como o signo de modernização da sociedade brasileira. Tornou-se, uma etapa do ensino, alvo de jogos de interesses das classes dirigentes. Em que pese a dinamicidade do ensino secundário, durante todo o período estudado (1931-1961), este significou “[...] a fase do processo educativo que corresponde à adolescência, ou que se superpõe à educação primária ou elementar; seria a educação do adolescente, como a educação primária é a da criança." (SILVA, 1969, p. 19). Ou seja, foi pensado para ser um nível de ensino intermediário, a fim de preparar a juventude para o ingresso no ensino superior.

O movimento da Escola Nova no Brasil teve grande influência sobre essas mudanças e reformas ocorridas no ensino secundário. Como movimento educacional, ganhou seus seguidores no início do século XX, adentrou a política educacional por meio do consumo, de jovens intelectuais, de literatura estrangeira, e seus ideais foram difundidos partir da década de 1920, associados diretamente ao pensamento liberal (NAGLE, 2011). Uma organização mais efetiva desses intelectuais no campo educacional ocorreu na década de 1930, culminando na publicação do "Manifesto dos Pioneiros da Educação Nova", no ano de 1932. O movimento criticou incisivamente o caráter humanístico do ensino secundário e a escola tradicional, denunciando uma educação elitista e 'inorganizada’, presente no cenário educacional brasileiro.

Apesar dessa ebulição no campo educacional ter se dado na década de 1930, ela não ocorreu instantaneamente. A pedagogia tradicional impregnada da visão católica, que se caracterizava pela simplicidade, análise e progressividade; formalismo; 
memorização; autoridade; emulação e intuição, começava a ser questionada pela Associação Brasileira de Educação - ABE já em 1924, quando foi criada.

A ABE promoveu debates e discussões sobre questões pedagógicas e circulação de intelectuais de grupos heterogêneos, facilitando a difusão das ideias pedagógicas escolanovistas que até então se apresentavam de forma tímida e dispersa, mas encabeçando algumas reformas estaduais.

A Reforma de Francisco Campos, de 1931, foi a primeira iniciativa de organização educacional abrangendo todo o território nacional. Objetivava organizar a educação e “[...] criar um ensino mais adequado à 'modernização' do país, com ênfase na capacitação para o trabalho e na formação das 'elites'." (MORAES, 1992, p. 133). Compreendia uma série de seis decretos; a Reforma Francisco Campos reformou o ensino comercial, o ensino secundário e o ensino superior, e criou o Conselho Nacional de Educação.

A reforma foi marcada principalmente pelos embates entre os dois principais grupos existentes no campo educacional. De um lado, escolanovistas; de outro, o grupo católico, que possuía a hegemonia educacional até então, devido à tradição adquirida por meio do apoio do governo e que era regida pelos princípios pedagógicos que constituíam uma pedagogia tradicional.

Com a finalidade de modernizar o ensino, a Reforma Francisco Campos dava maior organicidade para a cultura escolar do ensino secundário, com a adoção de medidas e normatizações como, por exemplo, a oficialização do exame de admissão, a divisão do curso em dois ciclos, o maior equilíbrio entre as disciplinas clássicas e científicas, a frequência mínima obrigatória, além de um rígido sistema de inspeção dos estabelecimentos e avaliação docente.

A reforma não apresentou significativas alterações nas concepções de ensinoaprendizagem, mantendo, por exemplo, a utilização de um conceito engessado de avaliação, como um instrumento de comprovação e verificação do aprendizado do aluno: "Art.34: "Haverá durante o ano letivo arguições, trabalhos práticos e, ainda, provas escritas parciais, com atribuição de nota, que será graduada de zero a dez" (BRASIL, 1931). Embora houvesse uma tentativa de apresentar inovações advindas do 
pensamento escolanovista, utilizando trabalhos práticos, não se conseguiu romper com a atribuição de nota baseada exclusivamente em escala numérica.

A reforma tentava articular os ideais liberais de industrialização e democracia ao nacionalismo, ao ideal de progresso e ao autoritarismo em âmbito estatal. Marcou uma contraditória aliança, que buscou intermediar os conflitos existentes entra a pedagogia tradicional e a pedagogia da Escola Nova, revelando um poder de resistência da pedagogia tradicional de caráter humanístico no cenário educacional.

A publicação do Decreto n. $19.890 / 31$ provocou a reação de intelectuais do movimento renovador, já no ano de 1931, tornando-se pauta das discussões e conferências promovidas pela $A B E$. A insatisfação advinda da reforma gerou, como resultado da $V$ Conferência Nacional de Educação, a encomenda de um documento que organizasse a proposta de ensino defendida pelos escolanovistas e consubstanciasse as discussões ocorridas em ocasião da referida Conferência. O Manifesto foi direcionado à população e ao governo, um documento com o qual "[...] procurava-se consolidar [...] a imagem de um grupo coeso, unido sob um código comum, inscrito na perspectiva escolanovista e informado por um mesmo ideal qual seja o empenho na construção de uma nação democrática." (XAVIER, 2012, p. 9-10).

O documento de 1932 contextualizou a dinâmica social do período, ao realizar o diagnóstico não somente de uma educação inorganizada, mas também de uma sociedade desorganizada, dispersa, desigual. Uma sociedade que sofria pela falta de um aparelho de cultura responsável por instrumentalizar as novas gerações para o avanço da ciência (MANIFESTO..., 1932).

Com isso, foi colocada em evidência a necessidade de uma educação baseada no culto à ciência experimental, a fim de adaptar o homem a essa nova sociedade, proporcionando a ela um progresso mecânico industrial. Enfatizava-se, por conseguinte, a formação de sujeito culto, com domínio de filosofia e sociologia. Que agregava na formação capacidade de inserção no mundo do trabalho, espírito colaborativo e solidário. Nesse sentido, houve um enfoque especial na crítica ao ensino secundário “[...] de tipo clássico, estritamente literário, o problema da educação nacional." (MANIFESTO..., 1932, p. 20). 
Como forma de eliminar estratificação social do ensino e a falta de harmonia entre os seus diferentes níveis, o manifesto propunha que a articulação em um sistema de ensino seria a solução para o elitismo da escola secundária. Ao criticar uma escola pensada pela e para a burguesia, o movimento reivindicava uma interpenetração de classes sociais e a valorização da dimensão pública do ensino. Como movimento construído sobre as bases liberais, apesar de haver uma crítica à estrutura do ensino, não sugeria à educação a finalidade de transformação, mas de adaptação social.

Com o ganho do Manifesto, iniciou-se a tentativa de superação da concepção de educação e de ensino aprendizagem nos moldes da escola tradicional, apresentando uma prática pedagógica que colocava o aluno como centro do processo educativo, respeitando sua personalidade, desenvolvida a partir de seus interesses e necessidades; a proposta, assim, conseguiu manter seu caráter moderno e inovador para aquele momento histórico.

No entanto, em 1942, a Reforma de Gustavo Capanema novamente focalizou o ensino humanístico. O segundo ciclo do ensino secundário foi reorganizado em clássico e científico, sendo que em ambos os cursos se atribuía notável importância ao ensino das línguas clássicas e modernas, que “[...] desempenhavam um papel importante na preservação da alta cultura." (SOUZA, 2009, p. 75). Dentre elas, o ensino de Português fez-se presente em todas as séries dos dois ciclos, no qual eram reforçados os valores de bem falar e bem escrever, convertidos "num símbolo de posse de capital cultural." (SOUZA, 2008, p. 177).

O golpe final para supremacia do ensino humanístico foi dado pela LDB de 1961; já em seu anteprojeto, a educação técnico-científica era colocada como questão fundamental para romper com o caráter elitista do currículo organizado pela reforma de Gustavo Capanema. Durante o período de elaboração do projeto e tramitação da lei, o ensino secundário foi gradativamente expandido com pequenas adequações, ações voltadas à ampliação do número de estabelecimentos e elevação do número de matrículas no ensino secundário, em busca da sua democratização e readequação para atender às necessidades econômicas do país. Em suma, foram programas e campanhas 
que se mostraram como uma forma de "preparar o terreno" para a recepção da publicação da LDB de 1961.

Assim, a LDB de 1961 contribuiu para algumas rupturas que a Escola Nova vinha reivindicando desde o Manifesto, mas que não haviam sido devidamente efetivadas nem na Reforma Francisco Campos nem na Reforma Capanema. Dessa forma, foi sendo descaracterizado gradualmente o ensino secundário como o reduto das elites oligárquicas, que tinha nessa etapa de ensino a ferramenta de legitimação de sua posição social.

\section{A formação escolar de agentes intelectuais no sul de Mato Grosso: leituras em fontes de memória}

Este tópico prossegue na discussão a respeito da formação escolar de agentes intelectuais, colocando-se em zoom especificidades locais e regionais. Para tanto, admite-se a necessidade de articular as questões regionais às questões que foram expressas no primeiro tópico por meio da identificação do lugar ocupado pelas instituições do sul de Mato Grosso frente ao processo maior de formação de agentes intelectuais.

O objetivo é compreender o panorama geral do ensino secundário no sul de Mato Grosso e aproximar trajetórias de agentes intelectuais a partir de suas obras memorialísticas e de seus relatos orais. Nesse contexto, o ensino secundário se destaca como parte de um projeto modernizador da região que tem início logo no começo do século XX.

Quadro 1 - Implantação das instituições de ensino secundário, no sul de Mato Grosso, no início do século XX

\begin{tabular}{|l|l|c|l|}
\hline Instituição & Cidade & Secundário & Iniciativa \\
\hline Instituto Pestalozzi & Campo Grande & 1917 & Privada \\
\hline Colégio Salesiano Santa Tereza & Corumbá & 1917 & Privada Confessional \\
\hline Colégio Imaculada Conceição & Corumbá & 1937 & Privada Confessional \\
\hline Colégio Nossa Senhora & Campo Grande & 1927 & Privada Confessional \\
\hline
\end{tabular}




\begin{tabular}{|l|l|c|l|}
\hline Auxiliadora & & & \\
\hline Ginásio Municipal Maria Leite & Corumbá & 1928 & Pública \\
\hline Colégio Oswaldo Cruz & Campo Grande & 1927 & Privada \\
\hline Liceu Campo Grandense & Campo Grande & 1938 & Pública \\
\hline
\end{tabular}

As primeiras instituições de ensino secundário foram implantadas inicialmente nas cidades de Corumbá e Campo Grande, acompanhando a dinâmica de formação de mercados regionais e o desenvolvimento econômico proporcionado pelo Porto de Corumbá e pela ferrovia Noroeste do Brasil.

O quadro 1 apresenta as primeiras instituições de ensino secundário implantadas na região sul de Mato Grosso. E, embora o Instituto Pestalozzi tenha inicialmente se apresentado com uma opção de instituição leiga, no ano de 1930 a instituição passou aos cuidados da missão salesiana e começou a ser chamada de Ginásio Municipal Dom Bosco.

As instituições salesianas encontraram solo frutífero para a missão educacional e se destacaram pela grande representatividade numérica em relação aos demais estabelecimentos de ensino, sendo a responsável pela formação escolar de grande parte dos intelectuais formados na região. Contou com dois estabelecimentos para moças: o Colégio Nossa Senhora Auxiliadora, na cidade de Campo Grande, e Colégio Imaculada Conceição na cidade de Corumbá. E dois estabelecimentos para rapazes: Colégio Dom Bosco na cidade de Campo Grande, e Colégio Santa Teresa na cidade de Corumbá.

Na direção do projeto modernizador para Mato Grosso, a década de vinte se mostrou bastante frutífera na porção sul do estado, onde ocorreu uma expansão do ensino secundário. É nesse momento histórico que, em Mato Grosso, colégios de ensino primário passam a oferecer o curso ginasial ao mesmo tempo em que teve lugar uma sequência, ainda que incipiente, de instalações de ginásios privados em Corumbá e Campo Grande. Entre 1917 e 1939, as cidades de Corumbá e Campo Grande tiveram implantados sete cursos ginasiais, é marcante o processo de aparecimentos de cursos ginasiais nas cidades de maior expressão econômica e política da região meridional. (OLIVEIRA, 2013, p. 3). 
Durante o processo de implantação dessas instituições, elaspassaram por um período marcado pela instabilidade e incerteza. Sofreram com mudanças de instalações, de proprietários, de nome e, principalmente, com as dificuldades de se adequarem em curtos espaços de tempo às sucessivas reformas realizadas no período, dificuldades essas maximizadas pela localização geográfica no interior do território brasileiro. Carregaram, no entanto, características pertencentes ao ensino secundário em contexto nacional, mantiveram uma característica comum: foram pensadas e organizadas para atender principalmente $\mathrm{o}$ interesse das classes dirigentes, promovendo um período frutífero de iniciativas em prol da institucionalização da legitimação das elites intelectuais locais.

Com isso, a implantação dessas instituições não somente proporcionou a construção do campo escolar da região, mas também o abastecimento do campo intelectual a partir de uma formação escolar de prestígio.

Bourdieu (2004) retrata um espaço social constituído por campos, que são microcosmos construídos a partir de interesses específicos dentro da sociedade, portanto, produto histórico de agentes sociais. Esses campos funcionariam de acordo com uma lógica própria, possuidores de uma relativa autonomia, “[...] cada campo de produção simbólica seria, então o palco de disputas - entre dominantes e pretendentes - relativas aos critérios de classificação e hierarquização dos bens simbólicos produzidos e, indiretamente das pessoas e instituições que os produzem." (NOGUEIRA; NOGUEIRA, 2009, p. 32).

Nesse campo é possível identificar a predominância de um tipo bastante específico de intelectuais, os escritores de obras memorialísticas. Esses escritores, inseridos em outros campos sociais, atuando como jornalistas, advogados, jornalistas, professores e políticos, foram agentes que não tinham a produção literária como sua principal fonte de sua subsistência. Autores diletantes que se apropriavam de um discurso de produção da arte pela arte, dedicando-se a produções sem fins lucrativos.

As produções culturais oriundas desse campo, embora apresentem divergências munidas pelas subjetividades dos indivíduos que as produziram, possuem alguns pontos 
de convergência que permitem indagar a função social dessas obras, dentre os quais se destacam dois.

Em um primeiro momento, nota-se a utilização das obras como veículo de promoção pessoal, no qual a mobilização de capitais (escolar e econômico) constituiu-se como uma ferramenta estratégica de aquisição de capital ${ }^{4}$ social e simbólico. Essa característica é notada mais nitidamente na escrita autobiográfica. Nesse gênero há um relato minucioso de fatos vividos a fim de "[...] fazer da sua vida uma obra de arte." (BOURDIEU, 2005, p. 185).

Em um segundo momento, observa-se a tentativa de dar visibilidade à porção sul do estado, valorizando atores, feitos, lugares e costumes específicos da região, criando uma identidade regional e ressaltando seus elementos modernos.

A partir desse período de implantação e organização do ensino secundário, ocorrido entre 1917 e 1939, no sul de Mato Grosso, o campo intelectual passou a ser alimentado por agentes com formação escolar secundária local. Esses novos agentes, que passaram a transitar no campo intelectual, tiveram atuação marcante principalmente após a divisão do estado de Mato Grosso (1977) e a criação de Mato Grosso do Sul, atuando para a criação de uma memória local e consolidação de uma identidade regional. Isso pode ser identificado principalmente quando,

[...] a partir de 1978, um verdadeiro "surto" memorialístico tomou corpo, desencadeando a publicação de inúmeras obras que construíram, mesmo que de maneira dispersa, uma numerosa e influente historiografia. Em pouco tempo, essa historiografia passou a se impor sobre outras referências, emergindo como fonte de estudo sobre o passado local para diversos setores da sociedade, principalmente para os profissionais das áreas de educação, comunicação, jornalismo e política, assim como serviu de suporte para a elaboração de livros didáticos, concursos públicos e como guia propagandas privadas e governamentais locais. (SILVA, 2006, p. 11).

\footnotetext{
4 “O capital - que pode existir no estado objectivado, em forma de propriedades materiais, ou, no caso do capital cultural, no estado incorporado, e que pode ser juridicamente garantido - representa um poder sobre um campo (num dado momento) e, mais precisamente, sobre o produto acumulado do trabalho passado (em particular sobre o conjunto dos instrumentos de produção, logo sobre os mecanismos que contribuem para assegurar a produção de uma categoria de bens e, deste modo, sobre um conjunto de rendimentos e de ganhos." (BOURDIEU, 2003, p. 134).
} 
Embora valiosas para o estudo de diversos campos do espaço social, essas obras memorialísticas não devem ser tomadas como produção historiográfica, pois expressam uma visão particular de um agente e seu grupo social, sem o rigor de método e análise científicos que são inerentes à historiografia acadêmica. No entanto, as produções robusteceram o campo intelectual e literário com sua ampla repercussão e contribuem significativamente com a produção historiográfica.

São esses agentes, com suas trajetórias de formação secundária e no campo intelectual, que cooperam para a identificação do papel do ensino secundário na formação e legitimação de agentes intelectuais que atuaram no sul de Mato Grosso.

Para as análises das fontes, consideram-se as especificidades da memória, a fim de torná-las fontes de pesquisa, pois mesmo as memórias constituídas a partir de lembranças individuais configuram-se como uma memória coletiva, por terem sido construídas no convívio e interação com amigos, parentes, familiares entre outros, pontos de referências externos que foram incorporados no decorrer da trajetória (HALBWACHS, 2006).

O processo de relembrar passa ainda por um delicado exercício de assimilação e reinterpretação, no qual são utilizados pontos de referências atuais. Em consequência disso, as lembranças de tempos remotos passam a ser lidas novamente a partir de uma nova percepção, o que revela o caráter de sua dinamicidade e a inexistência de uma memória pura, única, rígida e exata. Nesse sentido, as obras se alicerçam em um caráter de seletividade de memória tanto oral quanto escrita.

Os agentes contribuíram com a narrativa de uma trajetória escolar excelente, destacaram-se como bons alunos em diversas disciplinas do conhecimento, foram estudantes ativos e posteriormente ingressaram no campo intelectual com trânsito nos demais campos.

Devido a recente implantação do curso secundário na região, os autores, após estudarem em instituições da região, frequentaram instituições em outros estados para dar continuidade os estudos no segundo ciclo, que ainda eram indisponíveis nas poucas instituições de ensino secundário da região. Embora os agentes selecionados possuam 
posição no campo intelectual, que foi fomentada e iniciada nas instituições de ensino secundário, cabe mencionar que os três agentes tiveram percursos sociais e acadêmicos bem específicos.

Assim, as instituições escolares secundárias naquele momento histórico se configuravam como instituições de prestígio, inseridas na lógica de reprodução e legitimação das desigualdades sociais e escolares. Isso porque, tanto o processo de admissão quanto os custos de manutenção dos estudantes na escola elegiam um público seleto para ocupar as cadeiras escolares do ensino secundário.

Sobre o relacionamento com saberes escolares e a metodologia de ensino que compuseram essa formação, a análise prima por compreender o alcance da Escola Nova nessas instituições, que propunha o rompimento com o tradicionalismo da escola secundária, questionando o alcance do estudo dirigido, das autoavaliações, dos trabalhos em grupo e a utilização de laboratórios e músicas.

Indagado sobre as aulas, um dos autores afirma que: “[...] as aulas eram descritivas e de exposição... E de escrita no quadro, você copiava e discutia. Chamava o aluno lá na frente, fazia pergunta e ele tinha que responder. Fazia tarefa em casa, no caderno." (ADRI, 2016). Aqui é possível identificar elementos característicos da escola tradicional humanística, em que permaneceram a progressividade, o formalismo, a memorização, a autoridade, a emulação e a intuição.

O trabalho em grupo como técnica e como um dos passos básicos do método ativo $^{5}$, divulgado e defendido pela Escola Nova, no cotidiano escolar da formação das elites intelectuais, não aparece nas memórias dos entrevistados. Nas palavras dos agentes, o ensino era basicamente pela "[...] exposição oral. Não tinha trabalho em

\footnotetext{
${ }^{5}$ Metodologias ativas compreendem práticas de ensino que visam ao desenvolvimento de autonomia e participação dos alunos de forma integral, beneficiam o processo educativo e constituem modelos de ensino. Com isso, as práticas pedagógicas são beneficiadas e todo o processo educativo é melhorado, "[...] a espontaneidade, o jogo e o trabalho são elementos educativos sempre presentes: é por isso que depois foram chamadas de 'ativas'. São freqüentemente escolas nos campos, no meio dos bosques, equipadas com instrumentos de laboratório, baseadas no autogoverno e na cooperação, onde se procura ao máximo respeitar e estimular a personalidade da criança. Portanto, o conhecimento da psicologia infantil e da psicologia da idade evolutiva, tanto da criança individual como da infância e da adolescência em geral, como idade que tem em si suas leis e sua razão de ser, são temas essenciais da pedagogia das escolas novas." (MANACORDA, 1989, p. 305).
} 
grupo, a gente tinha aulas que não é como se faz hoje" (BARBOSA, 2017). Uma narrativa que vai ao encontro do quadro apresentado por Pierre Adri.

Os três autores afirmaram desconhecer os laboratórios no ensino secundário, ou mesmo os discos que ora deveriam ser utilizados nas aulas de línguas. Não foram identificados "[...] artefatos didáticos modernos, que chamo aqui de modernidades, tais como vitrolas, coleções de discos, coleções de livros, projetores de imagens fixas, slides e filmstrips, como parte de concretização do cenário de modernização desse nível de ensino." (RAHE, 2015, p. 24). Abílio Leite de Barros reforça: “Músicas eu não me lembro, mas eles davam textos para você ler e escrever sobre os textos. Textos de literatura. Mandavam a gente decorar poesia." (BARROS, 2017).

A falta de alcance do escolanovismo nas instituições de ensino do sul de Mato Grosso é observada, ainda, na dimensão da avaliação e da ação pedagógica. Nesse sentido, deixa-se de lado a autoavaliação e autorregulação, para um rígido ato de verificação do aprendizado. A avaliação tornava-se simples ato mecânico de memorização que envolvia a conversão do capital cultural em capital simbólico e escolar, ou cultural institucionalizado ${ }^{6}$.

Os ginasianos, no entanto, encaravam as avaliações como parte necessária e importante do processo de aprendizagem, e contam: “[...] você tinha muitas provas, né? Não tinha prova bimestral ou mensal. Tinha professor que dava toda aula. Era melhor porque você memorizava mais." (BARBOSA, 2017). A aprovação de José Barbosa às recorrentes atividades avaliativas e a um ensino baseado na memorização sugere um habitus $^{7}$ estudantil em harmonia com a lógica e as estratégias formativas da escola secundária.

\footnotetext{
${ }^{6} \mathrm{O}$ capital cultural institucionalizado é representado pela certificação escolar, materializado por diplomas sancionados por instituições educacionais. Bourdieu considera esse tipo de capital como uma "certidão de competência cultural." (BOURDIEU, 2012, p. 74-79). No entanto, há de se considerar que o diploma sem sua incorporação essencial, como conhecimento, informações, aquisição de saberes culturalmente legitimados não beneficiará o agente integralmente da potencialidade de sua certificação.

7 O habitus compreende um esquema estruturador de percepções do mundo social, ou seja, "[...] um sistema de esquemas de produção de práticas e um sistema de esquemas de percepção e apreciação das práticas. E, nos dois casos, suas operações exprimem a posição social em que foi construído. Em conseqüência, o habitus produz práticas e representações que estão disponíveis para a classificação, que são objetivamente diferenciadas; mas elas só são imediatamente percebidas enquanto tal por agentes que possuam o código, os esquemas classificatórios necessários para compreender-lhes o
} 
Estruturou-se um modo de ser e estar aluno, coerente com as exigências do campo educacional. A adequação de suas práticas proporcionou-lhe destaque e prestígio, tornando-se pertinente, consequentemente, sua defesa da escola secundária que foi responsável pela legitimação do lugar social que o agente ocupou e ainda ocupa.

Abílio Leite de Barros ainda relata a existência de um esquema de classificações realizado a partir das provas mensais. "Lá eles faziam muitas provas mensais de avaliação. Muitas vezes eu era o primeiro, o segundo, o terceiro. Estava sempre na área de cima. Mas tinha também gente muito boa (risos)." (BARROS, 2017). E José Barbosa contribui com seu relato, identificando uma nota específica que todos os alunos recebiam ao serem avaliados por sua disciplina e aplicação. Tais notas tornavam-se importante instrumento de avaliação, principalmente para os alunos internos, que poderiam ter negada a participação em atividades como festas e passeios caso as notas não estivessem em um patamar desejável.

O ritmo intenso de avaliações iniciava-se antes mesmo do ingresso na instituição, com o exame de admissão. A seleção era composta por uma banca de professores e um inspetor. A prova era realizada por meio de exames orais e escritos, com um caráter conteudista que se distanciava da realidade das crianças. Embora os autores relatem uma experiência tranquila para serem admitidos, escrevem em suas obras a respeito da importância e seletividade do exame, como exemplificado por um dos agentes, a seguir.

O exame de admissão ao ginásio era uma prova temida. Preparamo-nos com aflitiva aplicação decorando datas, números e conceitos. A banca era composta de quatro professores e um inspetor do Ministério da Educação. Exame oral, público. Nós já sabíamos que Cristóvão Colombo era um almirante genovês que partiu do porto de Palos em 1492. Que o gordo D. João VI mudou-se para o Brasil com medo de Napoleão. Que os verbos tinham pessoa, passado, presente, futuro, que eram transitivos, intransitivos, e outras variáveis, todas dentro do imperativo categórico da concordância. Sabíamos descrever a vida social dos índios e a soma dos ângulos internos de um triângulo. Tudo na ponta da língua. Assim era. (BARROS, 2004, p. 70).

sentido social." (BOURDIEU, 2004, p. 158). O habitus, portanto, está intrinsecamente relacionado à prática, tanto no momento de sua estruturação quanto no momento de sua exteriorização. 
Infere-se, a partir do relato, a importância do capital linguístico e cultural dentro do ensino tradicional de caráter humanístico da escola secundária, exigência essa que ignora os saberes de uma classe menos favorecida, que muitas vezes não chega sequer a tentar passar pelo exame de admissão. Isso porque, “[...] a linguagem é a parte mais inatingível da herança cultural [...] ela favorece um sistema de posturas mentais transferíveis, solidárias que com valores que dominam toda a experiência." (BOURDIEU, 2012, p. 56). Os exames orais eram uma das formas de avaliação da escola secundária, que inconscientemente, avaliava os alunos pela facilidade verbal, desenvoltura elegante e classificavam os agentes como aptos ou não.

Os autores ainda relataram gosto pela leitura e pelo estudo, anteriores à escola secundária, que tornavam mais profícuos os incentivos recebidos pela instituição relativos à leitura e à escrita. Nisso, as disciplinas de línguas presentes em todas as séries do curso secundário foram apontadas pelos três agentes como um diferencial do ensino a que tiveram acesso. Disciplinas essas que também se inseriam na lógica da produção do campo intelectual. Nesse sentido, o Francês recebia destaque pelo papel de instrumentalização ou até mesmo de pré-requisito para a inserção no campo intelectual.

Eu gostava de Francês, e era um bom aluno no Francês. Nas aulas de Francês eu estudava mais e era mais atento. Eu gostava muito de estudar francês e quando eu terminei o Ginásio eu praticamente já lia e já falava. Latim não. Não gostava. Inglês também eu estudava pouco. Porque a língua mais importante no meu tempo de ginásio e na minha adolescência era Francês. Era a língua internacional como é Inglês, hoje. Então o intelectual que não sabia francês não sabia nada. (BARROS, 2017, p. 229, grifo nosso).

Ao se reconhecer como intelectual, Abílio Leite de Barros identifica práticas específicas relacionadas ao ser e estar intelectual, proporcionando a interiorização de um hábito que o identificasse como pertencente ao campo. Práticas que estruturam e legitimam a ação no interior do campo intelectual. 
Oliveira (2009) contribui para a compreensão da valorização da língua, sua existência prática e sua utilização como instrumento político, técnico ou comercial, que são indicativas do reconhecimento de sua importância. A utilização do Francês na formação de agentes intelectuais se deve à tentativa de aproximação da cultura francesa. O estilo de viver em sociedade da elite francesa, associada ao bem falar, vestir, dançar, além das apreciações de música clássica, de obras de artes, de visitas a museus e de uma culinária refinada, são elementos, dentre outros, que compõem uma tradição culta.

A escola secundária continha estratégias de ampliação de capital cultural, simbólico e social, além de iniciação à vida política, incentivo à escrita e à leitura, que se mostraram significativas no percurso social e acadêmico dos agentes intelectuais apresentados no artigo.

Nesse processo, destacavam-se, ainda, o estímulo aos alunos para emulação, a dedicação, a disciplina e as boas notas. Estas eram expressas em passeios e prêmios que ampliavam o capital simbólico dos estudantes. Pierre Adri registrou que as condecorações eram realizadas no "Cinema Santa Helena”, em ocasiões solenes. "Lá a gente ganhava medalhas, a medalha de ouro, de prata, de bronze e menção honrosa para os alunos que se destacavam, honra ao mérito. Então chamava no meio do povo todo lá, e chamava lá na frente e colocava medalha." (ADRI, 2017).

O capital simbólico corresponde à conquista de uma reputação, no sentido de honra e prestígio, uma acumulação inserida em uma lógica específica, pois não pode ser adquirida a partir de ações mecanicamente calculadas ou conscientes. Insere-se, portanto, em uma lógica da prática fundada pelo reconhecimento das ações do agente (BOURDIEU, 2004). É, pois, um capital intrinsecamente relacionado à opinião e à representação de outros sobre os agentes.

Outras iniciativas presentes na escola secundária ainda contribuíram para a formação intelectual, tendo em vista a ampliação do capital cultural por meio do acesso a obras e músicas clássicas, nas disciplinas de Francês, Latim, Literatura, Inglês. Juntamente com a aquisição do capital cultural, o gosto pela leitura e a escrita era 
exercitado e estimulado nas disciplinas supramencionadas, por meio de recorrentes composições, passíveis de apreciação.

As agremiações também eram utilizadas como instrumento de ampliação de capitais. O Grêmio-Literário proporcionava a realização de peças teatrais, ampliando o capital cultural, aperfeiçoando a oratória e o exercício de falar em público. O livro de "Crônicas" do Colégio Santa Teresa, em que foram registradas as atividades do cotidiano da instituição, revela que no dia 9 de junho de 1941 houve, por exemplo, a fundação do Grêmio Dramático-Literário (CRÔNICA..., 1941). São assinaladas, também, apresentações e dramatizações de peças religiosas e clássicos da literatura. O Regimento de 1960 ainda reforça: “Art. 35 - a direção do colégio incentivará as iniciativas no setor cultural e prestigiará o funcionamento do grêmio-estudantil." (REGIMENTO..., 1960). O documento admite a possibilidade de que o grêmio tenha permanecido em funcionamento e contado com o incentivo institucional.

Pierre Adri foi o único estudante dentre os entrevistados a participar do grêmio estudantil, no Colégio Santa Teresa. Sem muitos detalhes, narra que: "A participação do grêmio era cultural. Representativo. Tinha uma festa de estudantes, representava. Tinha uma viagem, representava. Era assim." (ADRI, 2016).

Bourdieu (2014) contribuiu com o entendimento de que o grau de afinidade com os hábitos culturais de uma classe faz parte dos critérios decisivos para o sucesso escolar. "Uma maior ou menor afinidade entre os hábitos culturais de uma classe e as exigências do sistema de ensino ou os critérios que para ele definem o sucesso." (BOURDIEU, 2015, p. 39). Essa afinidade era estreitada pelas atividades ocorridas no grêmio, ainda que isso não implicasse uma relação direta de inserção no campo intelectual, mas sua facilitação.

O grêmio estudantil, juntamente com os impressos estudantis, além de estimularem o exercício da leitura e da escrita, iniciavam os alunos a participarem no campo político. Os grêmios constituíam-se como uma maneira legítima de reivindicação e exposição dos anseios dos alunos, além de estarem vinculados muitas vezes à produção de jornais estudantis. Tornavam-se, assim, um espaço de iniciação ao campo intelectual, em que, além da escrita, era exercitada a sua capacidade criativa. 
Essas atividades foram introduzidas, sobretudo, pelo pensamento escolanovista, e amparadas pela legislação, conforme o Artigo $46^{\circ}$. do Decreto-lei n ${ }^{\circ} 4.244 / 1942$ :

Os estabelecimentos de ensino secundário deverão promover, entre os alunos, a organização e o desenvolvimento de instituições escolares de caráter cultural e recreativo, criando, na vida delas, com um regime de autonomia, as condições favoráveis à formação do espírito econômico, dos bons sentimentos de camaradagem e sociabilidade, do gênio desportivo, do gosto artístico e literário. Merecerão especial atenção as instituições que tenham por objetivo despertar entre os escolares 0 interesse pelos problemas nacionais. (BRASIL, 1942, n.p.).

Em geral, o teor das publicações estudantis compreendia anúncios relativos ao colégio, poesias produzidas pelos estudantes, notícias esportivas, eventos cívicos escolares, notas políticas e culturais.

Relativamente às estratégias de ampliação do capital social, expressas em desfiles que reuniam alunos de diferentes instituições e em passeios, estes integravam estudantes de uma mesma instituição, de séries e turnos diferentes ou, em outras situações, estudantes de diferentes instituições.

Assim, os estabelecimentos escolares da região sul de Mato Grosso - Colégios Dom Bosco e Santa Teresa mobilizavam práticas escolares, culturais e sociais que possibilitavam a incorporação e estruturação de um habitus relacionado à arte de bem falar e bem escrever; bem como estratégias ampliação de capitais, que legitimavam o conhecimento e posição social dos agentes. A aquisição de tais conhecimentos e habilidades possibilitava o investimento desses recursos no campo intelectual, pois vinham ao encontro de sua lógica de funcionamento.

\section{Considerações finais}

As fontes levantadas e analisadas a respeito dos Colégios Dom Bosco e Santa Teresa evidenciaram práticas escolares empreendidas como estratégias de ampliação de capital cultural, simbólico e social, além de iniciação à vida política, incentivo à escrita e à leiturana trajetória dos agentes intelectuais. Considera-se, no entanto, que, embora a 
escola secundária proporcionasse os instrumentos necessários, não é possível deixar de ponderar a dimensão subjetiva dos agentes em questão.

Nesse sentido, considerando o conceito de habitus, como uma matriz de formação estruturada de maneira durável na socialização primária, ou seja, a instituição familiar, infere-se que, mesmo tendo recebido todos os incentivos necessários, nem todos os agentes que passaram pela escola secundária apresentavam as disposições necessárias para a constituição do ser intelectual, a fim de construir novas estruturas a partir dos incentivos da escola.

A investigação das fontes sobre o ensino secundário ainda evidenciou aulas, sobretudo expositivas, tendo o professor como o centro do processo educativo e detentor do conhecimento, responsável por transmiti-lo. Um ensino que abrangia métodos de ensino notadamente tradicionais marcados pela memorização, cópias e extensas tarefas para a casa, em um cenário que se contrapunha àquele preconizado pela Escola Nova, com a defesa do professor facilitador, a utilização do método ativo, e o estudante no centro do processo de ensino-aprendizagem.

A modernização do ensino e o processo avaliativo também se mostraram alheios às transformações ocorridas no campo. Os laboratórios, as visitas a museus e as bibliotecas pareceram passar distante da trajetória dos agentes entrevistados. E, de igual modo, distanciava-se também o processo avaliativo, que esteve baseado em uma mera verificação da aprendizagem medida por números e menções.

Considera-se, ainda, que embora a escola secundária no sul de Mato Grosso apresentasse fragilidades consideráveis, com processo de implantação tardio e uma tentativa de organização e adequação tumultuadas, localizadas em cidades em desenvolvimento, com corpo docente muitas vezes minguado e sem as qualificações exigidas pelo sistema - cumpriu o papel de legitimação das desigualdades sociais, e proporcionou aos jovens economicamente favorecidos uma maior distinção social, por meio do acúmulo de capitais e certificação escolar, que na sociedade capitalista são mobilizados como instrumento de dominação. 


\section{Referências}

ADRI, Pierre. Entrevista em 24 de abril, 2016. [Entrevista cedida a] ANDRADE, Heloise Vargas. Ensino secundário e agentes intelectuais no sul de Mato Grosso (1931-1961). Campo Grande, 2017. 28op. Dissertação (Mestrado em Educação) - Universidade Federal de Mato Grosso do Sul.

BARBOSA, José Corrêa. Entrevista em 04 de dezembro, 2016. [Entrevista cedida a] ANDRADE, Heloise Vargas. Ensino secundário e agentes intelectuais no sul de Mato Grosso (1931-1961). Campo Grande, 2017. 280p. Dissertação (Mestrado em Educação) Universidade Federal de Mato Grosso do Sul.

BARROS, Abílio Leite. Entrevista em 21 de abril, 2016. [Entrevista cedida a] ANDRADE, Heloise Vargas. Ensino secundário e agentes intelectuais no sul de Mato Grosso (19311961).Campo Grande, 2017. 28op. Dissertação (Mestrado em Educação) - Universidade Federal de Mato Grosso do Sul.

BARROS, Abílio Leite. História de muito antes. Campo Grande: Editora Uniderp, 2004.

BOURDIEU, Pierre. A economia das trocas simbólicas. São Paulo: Perspectiva, 2005.

BOURDIEU, Pierre. O capital social - notas provisórias. In: BOURDIEU, Pierre. Escritos de educação. 13. ed. Petrópolis, RJ: Vozes, 2012.

BOURDIEU, Pierre. O poder simbólico. Rio de Janeiro, Bertrand Brasil, 2003.

BOURDIEU, Pierre; PASSERON, Jean-Claude. Os herdeiros: os estudantes e a cultura. Trad. Ione Ribeiro Valle e Nilton Valle. Florianópolis: Editora da UFSC, 2014.

BOURDIEU. Coisas ditas. Trad. Cássia R. da Silveira e Denise M. Pegorim. São Paulo: Brasiliense, 2004.

BRASIL. Decreto n ${ }^{\circ} 19.890$, de 18 de Abril de 1931. Dispõe sobre a organização do ensino secundário. Brasília, DF: Câmara dos Deputados, 1931. Disponível em: www2.camara.gov.br. Acesso em: 23 abr.2016.

BRASIL. Decreto-Lei 4.244 de 9 de Abril de 1942. Lei orgânica do ensino secundário. Brasília, DF: Câmara dos Deputados, 1942. Disponível em: www2.camara.gov.br. Acesso em: 15 abril de 2016.

CRÔNICA do Ginásio Santa Teresa, 1936. Corumbá, MT: Livro de Crônicas, 1941. 
HALBWACHS, Maurice. A memória coletiva. Tradução de SIDOU, Beatriz. 2. ed. São Paulo: Centauro, 2006.

MANACORDA, Mário Alighiero. História da Educação: da Antiguidade aos nossos dias. 12 ed. São Paulo: Cortez, 2006.

MANIFESTO dos pioneiros da educação nova:a reconstrução educacional no Brasil; a povo e ao Governo. São Paulo: Companhia Editora Nacional, 1932.

MORAES, Maria Célia Marcondes de. Educação e política nos anos 30: a presença de Francisco Campos. Revista Brasileira de Estudos Pedagógicos, Brasília, v. 73, n, 174, p. 291-321, maio/ago. 1992. Disponível em:

http://rbep.inep.gov.br/ojs3/index.php/rbep/article/view/1093 Acesso em: 20 de junho de 2017.

NAGLE, Jorge. Educação e sociedade na Primeira República. São Paulo: EPU; Rio de Janeiro: Fundação Nacional de Material Escolar, 2011.

NOGUEIRA, Maria Alice; NOGUEIRA, Claudio M. Martins. Bourdieu\& a educação. 3. ed. Belo Horizonte: Autêntica, 2009.

OLIVEIRA, Stella Sanches de. A história da disciplina escolar francês no Colégio Estadual Campo-grandense (1942-1962). 2009. 250p. Dissertação (Mestrado em Educação) Universidade Federal de Mato Grosso do Sul, Campo Grande, MS, 2009.

OLIVEIRA, Stella Sanches. Educação secundária confessional e laica no sul de Mato Grosso: Colégio Imaculada Conceição e Liceu Campograndense. In: CONGRESSO BRASILEIRO DE HISTÓRIA DA EDUCAÇÃO: Circuitos e fronteiras da História da Educação no Brasil, 7., 2013. Cuiabá/MT. Anais[...] Cuiabá: UFMT, 2013, p. 1-13. Disponível em: http://sbhe.org.br/novo/congressos/cbhe7/pdf/07\%20HISTORIA\%20DAS\%20INSTITUICOES \%20E\%20PRATICAS\%20EDUCATIVAS/EDUCACAO\%20SECUNDARIA\%20CONFESSIONAL\%20 E\%20LAICA\%20NO \%20SUL\%20DE\%20MATO.pdf. Acesso em: 17 junho de 2016.

RAHE, Marta Banducci. Inovações incorporadas ou "modernidade abandonadas"?: uma investigação sobre os materiais didáticos para as aulas de Línguas vivas em dois ginásios de Campo Grande, Sul do Estado de Mato Grosso (1931-1961). Campo Grande, 2015. 199 f. Tese (Doutorado em Educação) - Universidade Federal de Mato Grosso do Sul.

REGIMENTO Interno do Colégio Salesiano Santa Teresa. Corumbá, MT: [s.n.], 1960.

SILVA, Geraldo Bastos. A educação secundária: perspectiva histórica e teoria. São Paulo: Editora Nacional, 1969. 
SILVA, Ricardo Souza. Mato Grosso do Sul: labirintos da memória. Dourados, 2006. $120 f$. Dissertação (Mestrado em Educação) - Universidade Federal da Grande Dourados, 2006.

SOUZA, Rosa Fátima de. A renovação do currículo do ensino secundário no Brasil: as últimas batalhas pelo humanismo (1920-1960). Currículo sem Fronteiras, v.9, n.1, p.7290, jan./jun., 2009. Disponível em:

http://www.curriculosemfronteiras.org/volgiss1articles/4-souza.pdf. Acesso em: 8 junho de 2015.

SOUZA, Rosa Fátima de. História da organização do trabalho escolar e do currículo no século XX (ensino primário e secundário no Brasil). São Paulo: Cortez, 2008.

XAVIER, Maria do Carmo. A educação no debate do desenvolvimento: as décadas de 1950 e 1960. In: GIL, Natália; ZICA, Matheus da Cruz; FARIA FILHO, Luciano Mendes (org.). Moderno, modernidade e modernização:a educação nos projetos de Brasil séculos XIX e XX. Belo Horizonte, MG: Mazza Edições Ltda., 2012.p. 205-232.

Recebido em: 24/09/2019

Aprovado em: 12/06/2020

Universidade do Estado de Santa Catarina - UDESC

Centro de Ciências Humanas e da Educação - FAED

Revista PerCursos

Volume 21 - Número 45 - Ano 2020 revistapercursos@gmail.com 